\title{
BMJ Open What is the best way to keep walking and moving around for individuals with Machado-Joseph disease? A scoping review through the lens of Aboriginal families with Machado-Joseph disease in the Top End of Australia
}

Jennifer J Carr, ${ }^{1}$ Joyce Lalara, ${ }^{2}$ Gayangwa Lalara, ${ }^{2}$ Moira Smith, ${ }^{3}$ Jennifer Quaill, ${ }^{3}$ Alan R Clough, ${ }^{4}$ Anne Lowell, ${ }^{5}$ Ruth N Barker ${ }^{1}$

To cite: Carr JJ, Lalara J, Lalara G, et al. What is the best way to keep walking and moving around for individuals with Machado-Joseph disease? A scoping review through the Iens of Aboriginal families with Machado-Joseph disease in the Top End of Australia. BMJ Open 2019;9:e032092. doi:10.1136/ bmjopen-2019-032092

- Prepublication history and additional material for this paper are available online. To view these files, please visit the journal online (http://dx.doi. org/10.1136/bmjopen-2019032092).

Received 05 June 2019 Revised 30 July 2019 Accepted 02 August 2019
Check for updates

(C) Author(s) (or their employer(s)) 2019. Re-use permitted under CC BY-NC. No commercial re-use. See rights and permissions. Published by BMJ.

For numbered affiliations see end of article.

Correspondence to

Jennifer J Carr;

jennifer.carr2@my.jcu.edu.au

\section{ABSTRACT}

Objectives Machado-Joseph disease (MJD) is the most common spinocerebellar ataxia worldwide. Prevalence is highest in affected remote Aboriginal communities of the Top End of Australia. Aboriginal families with MJD from Groote Eylandt believe 'staying strong on the inside and outside' works best to keep them walking and moving around, in accordance with six key domains that form the 'Staying Strong' Framework. The aim of this current study was to review the literature to: (1) map the range of interventions/strategies that have been explored to promote walking and moving around (functional mobility) for individuals with MJD and; (2) align these interventions to the 'Staying Strong' Framework described by Aboriginal families with MJD.

Design Scoping review.

Data sources Searches were conducted in July 2018 in MEDLINE, EMBASE, CINAHL, PsychINF0 and Cochrane Databases.

Eligibility criteria for selecting studies Peer-reviewed studies that (1) included adolescents/adults with MJD, (2) explored the effects of any intervention on mobility and (3) included a measure of mobility, function and/or ataxia were included in the review.

Results Thirty studies were included. Few studies involved participants with MJD alone (12/30). Most studies explored interventions that aligned with two 'Staying Strong' Framework domains, 'exercising your body' $(n=13)$ and 'searching for good medicine' $(n=17)$. Few studies aligned with the domains having 'something important to do' $(n=2)$ or 'keeping yourself happy' $(n=2)$. No studies aligned with the domains 'going country' or 'families helping each other'.

Conclusions Evidence for interventions to promote mobility that align with the 'Staying Strong' Framework were focused on staying strong on the outside (physically) with little reflection on staying strong on the inside (emotionally, mentally and spiritually). Findings suggest future research is required to investigate the benefits of lifestyle activity programmes that address both physical and psychosocial well-being for families with MJD.

\section{Strengths and limitations of this study}

- This is the first review to map interventions trialled for individuals with Machado-Joseph disease (MJD) to enhance walking and moving around and to align findings with the 'Staying Strong' Framework.

- Studies typically focussed on interventions that promote 'staying strong on the outside' (physically), with few targetting 'staying strong on the inside' (emotionally, mentally and spiritually).

- This study is limited by a shortage of high-quality research that includes individuals specifically with MJD.

- This review highlights opportunities for investigating the benefit of lifestyle activity programmes that address both physical and psychosocial well-being for families with MJD.

\section{INTRODUCTION}

Machado-Joseph disease (MJD), or spinocerebellar ataxia type 3 , is an autosomal-dominant neurodegenerative disease. Individuals with MJD experience progressive cerebellar ataxia and decline in mobility caused by premature cell death in the cerebellum and brainstem. ${ }^{1}$ Average life expectancy is 20 years from onset of symptoms, with most individuals wheelchair users within 10 years of symptoms emerging. ${ }^{2} \mathrm{MJD}$ is the most common spinocerebellar ataxia (SCA) worldwide ${ }^{3}$ and is most prevalent in remote Aboriginal communities in the Top End of Australia. For example, prevalenace estimates for the Groote Eylandt Archipelago in Australia are $743 / 100$ 000, compared with $\sim 39 / 100000$ for the Azores Archipelago in Portugal, where MJD is also common. ${ }^{4-7}$ 
Many trials are underway to find a cure for a range of SCAs. ${ }^{89}$ Other research efforts have focused on physiotherapeutic interventions to address impairments and activity limitations resulting from a range of hereditary ataxias (HAs) ${ }^{10-13}$ These interventions have been shown to enhance mobility and potentially delay symptom progression. ${ }^{14}$ For people with $\mathrm{MJD}$, current recommended physiotherapeutic interventions are based on findings from studies on other SCAs. ${ }^{13}{ }^{15-17}$ A focus on MJD is required, given the differences in pathophysiology and neurochemistry between SCA types, ${ }^{9}$ and to understand what interventions have been previously explored and where gaps lie. This information will provide future direction for targeted interventions for people with MJD to maximise their functional mobility.

Interventions designed to promote mobility for Aboriginal families with MJD from the Top End of Australia, whose culture and lifestyle are uniquely different to those with MJD in other parts of the world, have not been investigated. ${ }^{18}$ Importantly, these interventions are unlikely to be effective if they do not incorporate Indigenous views and concepts of physical activity and lifestyle in line with cultural and traditional practices. ${ }^{18-20}$

Aboriginal families with MJD from the Groote Eylandt Archipelago have experienced the impact of MJD on their families for generations. ${ }^{18}$ In a recent study, ${ }^{21}$ these families shared their perspectives on what is important and what works best to keep walking and moving around. ${ }^{18}$ Participants emphasised the importance of 'staying strong on the inside and outside' (physically, mentally, emotionally and spiritually) through 'exercising your body', 'keeping yourself happy', 'going country', 'searching for good medicine', 'families helping each other' and having 'something important to do'. ${ }^{18}$ These domains formed the 'Staying Strong' Framework to keep walking and moving around; a framework driven by community and culturally founded needs (table 1 ). ${ }^{18}$ This review set out to explore: (1) What interventions/strategies have been explored to promote walking and moving around for people with MJD (2); How the findings of these explorations align with the perspectives of families with MJD from Groote Eylandt, according to the domains of the 'Staying Strong' Framework. ${ }^{18}$

\section{METHODS AND ANALYSIS}

A scoping review was conducted following the five-step approach recommended by Arksey and O'Malley and further developed by Levac et $a l^{22}{ }^{23}$ A scoping review was chosen to allow a broad range of topics across a range of study types and designs to be explored, to identify the nature and extent of research evidence available. ${ }^{24}$ The Preferred Reporting Items for Systematic reviews and Meta-Analyses (PRISMA) extension for Scoping Reviews

\begin{tabular}{|c|c|}
\hline Domains & Definition \\
\hline $\begin{array}{l}\text { Exercising } \\
\text { your body }\end{array}$ & $\begin{array}{l}\text { Having an active lifestyle and keeping your body moving every day keeps you physically strong (ie, going } \\
\text { country, walking, hunting, fishing swimming, dancing, doing housework and yard work, riding a bike, } \\
\text { walking on a treadmill). } \\
\text { Exercising your body helps you cope with the worries and sadness that come with MJD. }\end{array}$ \\
\hline $\begin{array}{l}\text { Something } \\
\text { important to } \\
\text { do }\end{array}$ & $\begin{array}{l}\text { Finding something meaningful to do pushes you to keep your body moving and keep physically strong. } \\
\text { Having something important to do helps you feel you are contributing to your family and community, sets } \\
\text { an example for others and builds self-esteem and happiness. }\end{array}$ \\
\hline $\begin{array}{l}\text { Keeping } \\
\text { yourself happy }\end{array}$ & $\begin{array}{l}\text { Finding ways to stay happy and positive, and drawing on family and support services when required, helps } \\
\text { you keep persevering in life despite having MJD. } \\
\text { It helps you to keep doing the things you need to do to stay physically strong. } \\
\text { Feeling low and unhappy can make you feel physically weak. }\end{array}$ \\
\hline Going country & $\begin{array}{l}\text { Going country means getting out and about, to places meaningful to the individual, to do things that matter, } \\
\text { with people that matter, to keep yourself both physically and emotionally strong. } \\
\text { For Aboriginal families of Groote Eylandt, going country involves getting out of the home, visiting their } \\
\text { lands, at the bush or beach, often to go hunting or fishing with family. }\end{array}$ \\
\hline $\begin{array}{l}\text { Families } \\
\text { helping each } \\
\text { other }\end{array}$ & $\begin{array}{l}\text { Family support is important for having opportunities to keep physically strong and for physical assistance } \\
\text { as the disease progresses. } \\
\text { Support from families offers important emotional support, keeping you strong inside. } \\
\text { Family extends to local and trusted service providers. }\end{array}$ \\
\hline
\end{tabular}

MJD, Machado-Joseph disease. 
Table 2 Search terms (MEDLINE)

\begin{tabular}{|c|c|c|}
\hline Concept & Search terms & Limits \\
\hline $\begin{array}{l}\text { What } \\
\text { (interventions) }\end{array}$ & $\begin{array}{l}\text { program }^{\star} \text { or promot* or interven* or strateg* or approach* or train* or rehab* or princip* or } \\
\text { therap }{ }^{\star} \text { or support }{ }^{\star} \text { or motivat* }\end{array}$ & Nil \\
\hline $\begin{array}{l}\text { People with MJD } \\
\text { (initially broadened } \\
\text { search to HAs to ensure } \\
\text { all studies that may have } \\
\text { included participants with } \\
\text { MJD could be screened) }\end{array}$ & $\begin{array}{l}\text { cerebellar ataxia/ or exp spinocerebellar ataxias/ or spinocerebellar degenerations/ } \\
\text { or friedreich ataxia/ or olivopontocerebellar atrophies/ or 'spinocerebellar ataxia*' or } \\
\text { 'machado joseph disease' or 'friedreich's ataxia' or 'inherited olivopontocerebellar } \\
\text { atrophy' or 'cerebello-olivary atrophy' or 'spinocerebellar degeneration' or 'genetic } \\
\text { degenerative ataxia' or 'cerebellar ataxia' or 'hereditary ataxia' or 'genetic ataxia' } \\
\text { or 'inherited ataxia' or 'dentatorubral pallidoluysian atrophy' or 'trinucleotide repeat } \\
\text { dis*' or 'inherited neurodegenerative dis" or 'degenerative ataxia' or 'hereditary } \\
\text { neurodegenerative ataxia*' or 'autosomal dominant hereditary ataxia*' or 'autosomal } \\
\text { recessive hereditary ataxia*' }\end{array}$ & Nil \\
\hline
\end{tabular}

HAs, hereditary ataxias; MJD, Machado-Joseph disease.

Checklist was followed. ${ }^{25}$ This review was not registered with PROSPERO as scoping reviews are not currently accepted.

\section{Relevant studies}

A comprehensive search of peer-reviewed published literature was conducted for studies published from 1990 when genetic confirmation of MJD became possible, ${ }^{26} 27$ until August 2018. The search was repeated prior to publication to identify studies published up to July 2019. Using MEDLINE, EMBASE, CINAHL, PsychINFO and Cochrane Databases, a combination of medical subject headings terms and keywords with truncations were used (table 2). The search was initially broad to include all HAs, to ensure inclusion of studies with participants with multiple aetiologies including MJD would be identified. Studies were chosen if they (1) included human participants with genetically confirmed MJD either exclusively or within the study sample, (2) included adolescents and/ or adults, (3) included at least one measure of mobility, function or ataxia and (4) explored the influence of any intervention/strategy on mobility and/or function using objective measures or from the perspective of the participant. In studies that did not disclose the types of SCA of included participants, authors were contacted to confirm inclusion or exclusion on this basis.

\section{Study selection and quality assessement}

Database searches were conducted by one reviewer (JJC) and verified by a second reviewer (JQ). Both reviewers (JJC and JQ) independently screened titles and abstracts and reviewed full-text articles. Additional studies screened for inclusion were identified by handsearching reference lists of included studies, literature reviews that met the eligibility criteria and through citations tracked using Google Scholar. $^{18911121428-31}$ The PRISMA flow diagram outlines the results of the search (figure 1). ${ }^{32}$ The second search found no new studies that met the inclusion criteria.

Methodological quality assessment of included studies, not typically required of scoping reviews, was employed to identify gaps in the literature and quality of the studies available. ${ }^{33}$ Two reviewers (JJC and MS) assessed methodological quality of included studies using the Mixed Method Appraisal Tool (MMAT) ${ }^{34}$ and classified them according to the National Health and Medical Research Council (NHMRC) evidence hierarchy. ${ }^{35}$ The MMAT was selected as this single tool allowed quality appraisal of the range of study designs relevant to this review (qualitative, randomised controlled (RCTs), non-RCTs and quantitative descriptive studies). Joanna Briggs Institute (JBI) Levels of Evidence for Meaningfulness ${ }^{36}$ was used to grade level of evidence for the qualitative study ${ }^{37}$ and the expert opinion excerpt. ${ }^{1}$ Disagreements were resolved by consensus or referred to a third reviewer (RNB).

\section{Data extraction, collation and analysis}

To facilitate analysis and reporting, data were extracted using NVivo V.12 $2^{38}$ following a data extraction guide. Data extracted included study characteristics, participant characteristics, intervention characteristics, outcome measures and study outcomes. Data gathered were charted into tables. ${ }^{22}$ Measures of blood chemistry, neuroimaging or measures of upper limb function were not extracted unless included in composite or functional outcome measures, such as the Spinocerebellar Ataxia Functional Index (SCAFI).

All studies found were collated and then mapped according to the domains they aligned to in the 'Staying Strong' Framework (JJC). Studies that aligned to more than one domain were mapped under the domain to which they most strongly aligned (table 3). A descriptive approach was used to analyse the data collected. ${ }^{39}$ To 


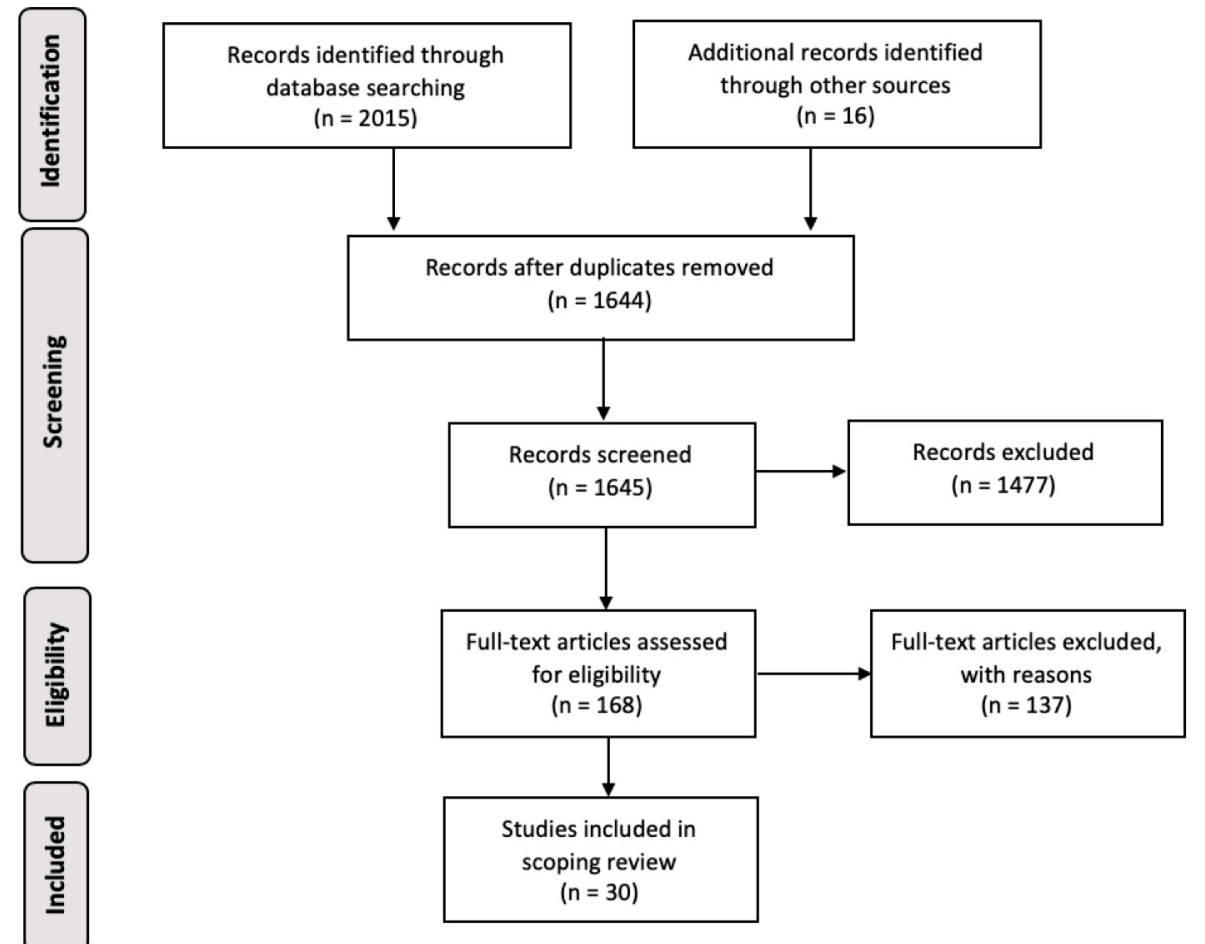

Figure 1 Flow diagram of study selection.

provide an overview, key points that highlight each study's alignment with the different domains were compiled in a separate table (online supplementary table 1). Meta-analysis was not possible due to heterogeneity of outcome measures and interventions in the included studies.

\section{Patient and pubic involvement}

There was no patient or public involvement in this study.

\section{RESULTS}

A total of 30 studies met the eligibility criteria and included quantitative (experimental $(\mathrm{n}=27)$; observational $(\mathrm{n}=1))$ and qualitative $(\mathrm{n}=1)$ designs. One expert opinion excerpt $(n=1)$ that was eligible and included was extracted from a literature review that otherwise did not meet the eligibility criteria. Twelve different countries were represented (Brazil $(n=6)$, Germany $(n=4)$, China $(\mathrm{n}=3)$, Japan $(\mathrm{n}=3)$, Taiwan $(\mathrm{n}=3)$, USA $(\mathrm{n}=3)$, India $(n=2)$, Italy $(n=2)$, Spain $(n=2)$, Korea, the Netherlands and Scandinavia. Characteristics of the included studies are outlined in table 3 .

\section{Study population}

Of the 30 studies, 12 studies included MJD participants exclusively. The remaining 18 included participants with both MJD and other HAs. Mobility status was reported as ambulant in 21 studies, able to stand at a minimum in one study, while eight studies did not report mobility status. Study sample sizes ranged from eight to 295 participants, with a total of 850 participants, 429 with MJD (50.5\%). Age ranged from 15 to 76 (average across all studies $=46.7$ years $)$.

\section{Methodological quality}

Seven quantitative studies were graded level II (RCTs) according to NHMRC levels of evidence. ${ }^{30} 40-45$ The remaining studies were graded III-1 (one study), ${ }^{46}$ III-2 (three studies), ${ }^{47-49}$ III-3 (one study) ${ }^{50}$ and IV (16 studies). ${ }^{51-66}$ The qualitative study was graded level $3^{37}$ and the expert opinion excerpt was graded level $5^{1}$ in accordance with the JBI Levels of Evidence for Meaningfulness. ${ }^{36}$ MMAT scores for methodological quality are provided in table 4. Quality scores ranged as follows $*(\mathrm{n}=1),{ }^{48} * *(\mathrm{n}=6),{ }^{414351545864 * * *}(\mathrm{n}=10)^{30374445495053576366}$ and **** $(\mathrm{n}=12) .4042464752555659-6265$ The expert opinion excerpt was not scored. ${ }^{1}$

\section{Outcome measures}

Fifty-three different outcome measures were used to investigate interventions in this review. The SARA scale (14/30 studies) was the measure most commonly used. Outcome measures included measures at the impairment level (ataxia, disease severity and depression), measures at the activity level (function, mobility and balance) and measures of quality of life (QOL). No studies included measures at the participation level. Table 5 presents measures used, as well as outcomes that reached statistical significance.

\section{Adverse events}

Nine studies reported adverse events, all within pharmacological studies. None were considered serious or life threatening. ${ }^{30} 4142444553556466$ One study reported two-drop outs due to side effects, but details of the effects were not specified. ${ }^{64}$ 


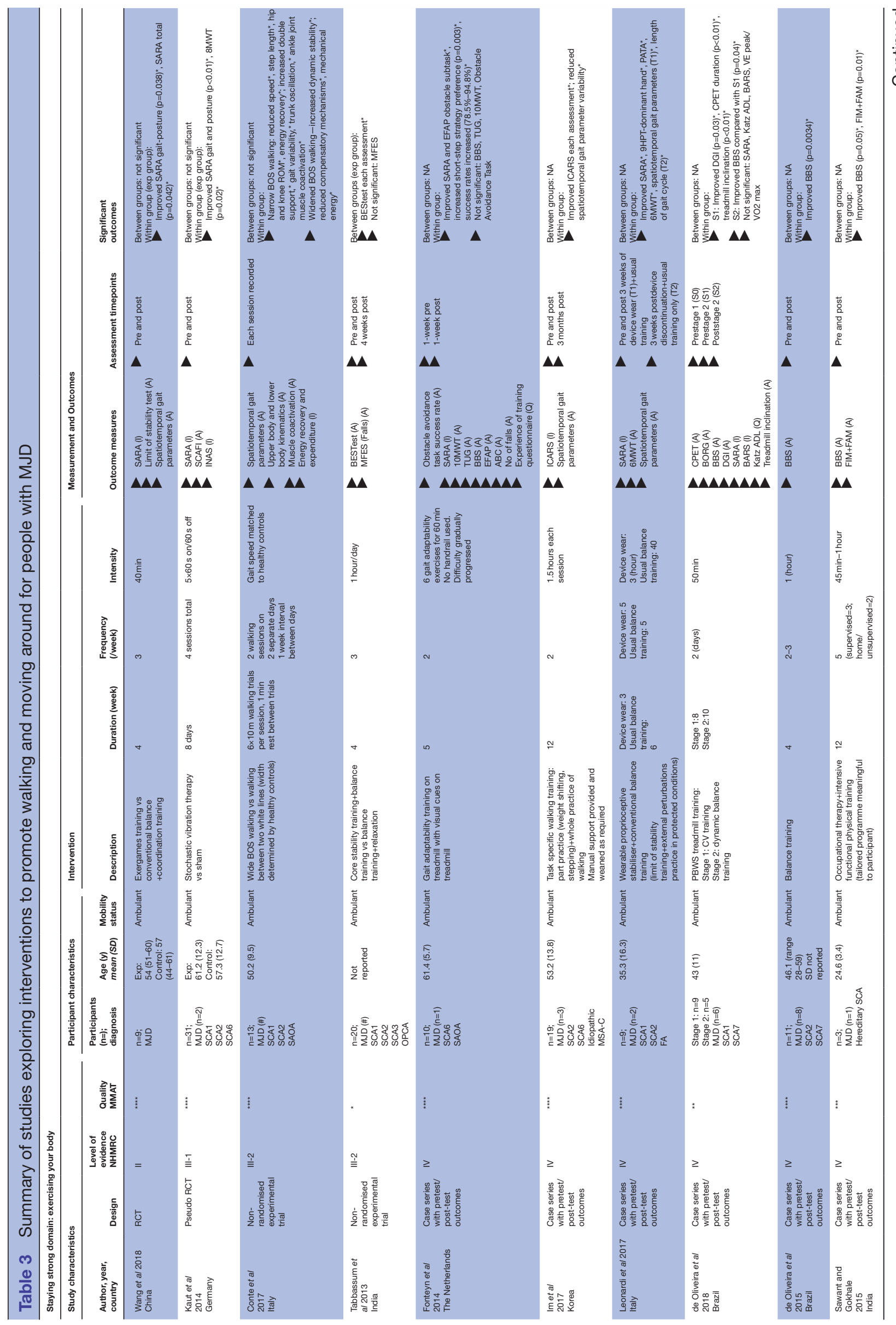




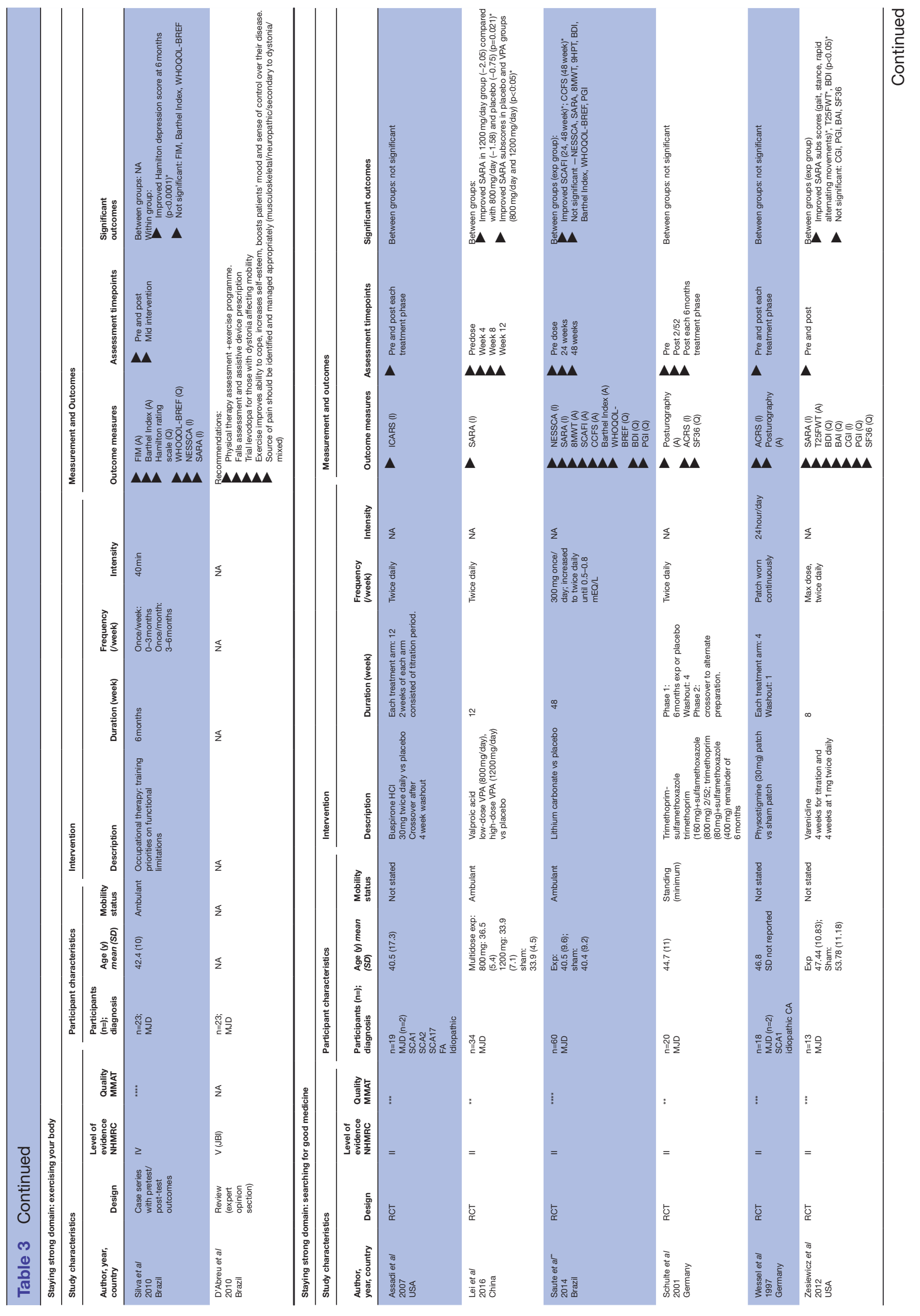




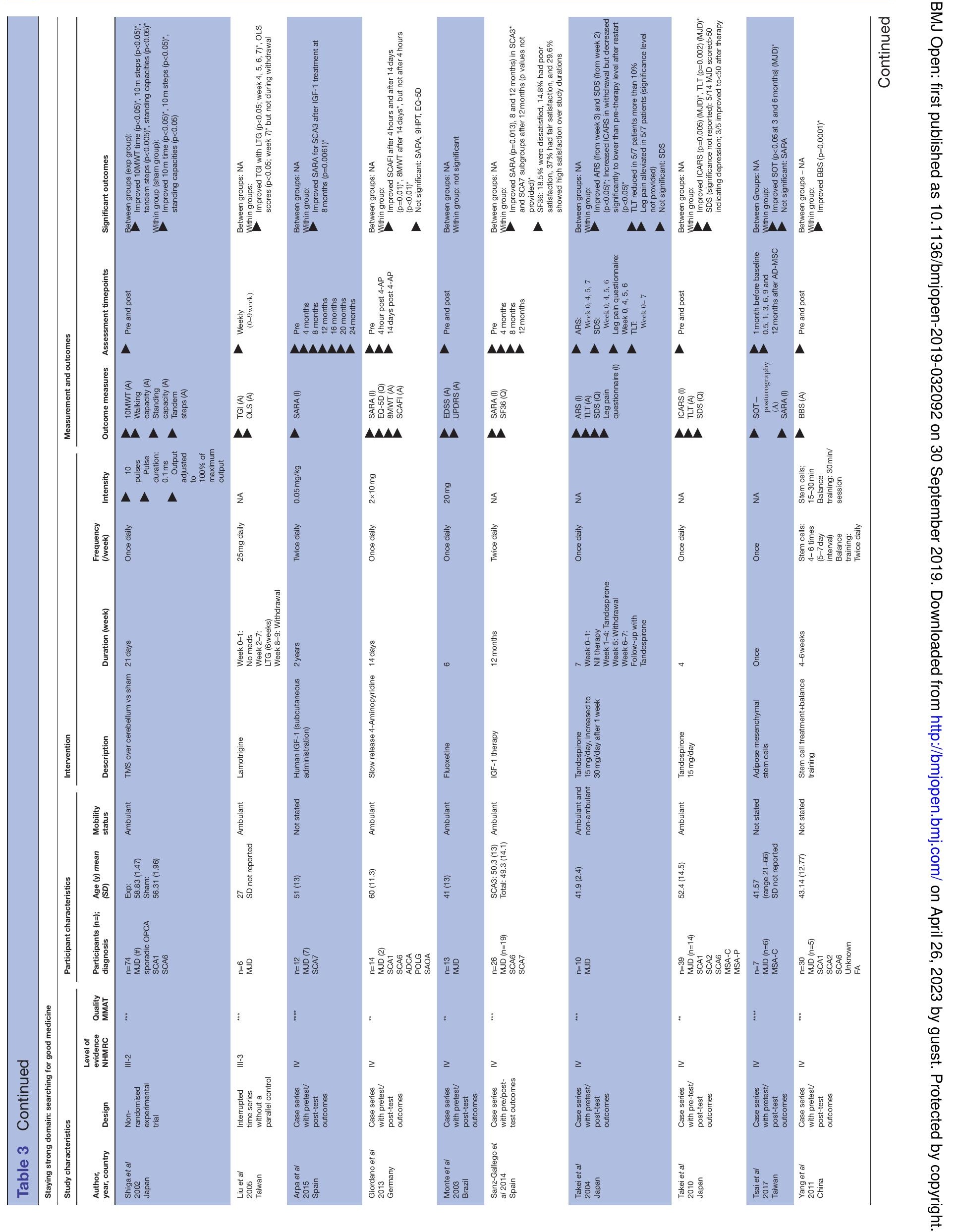




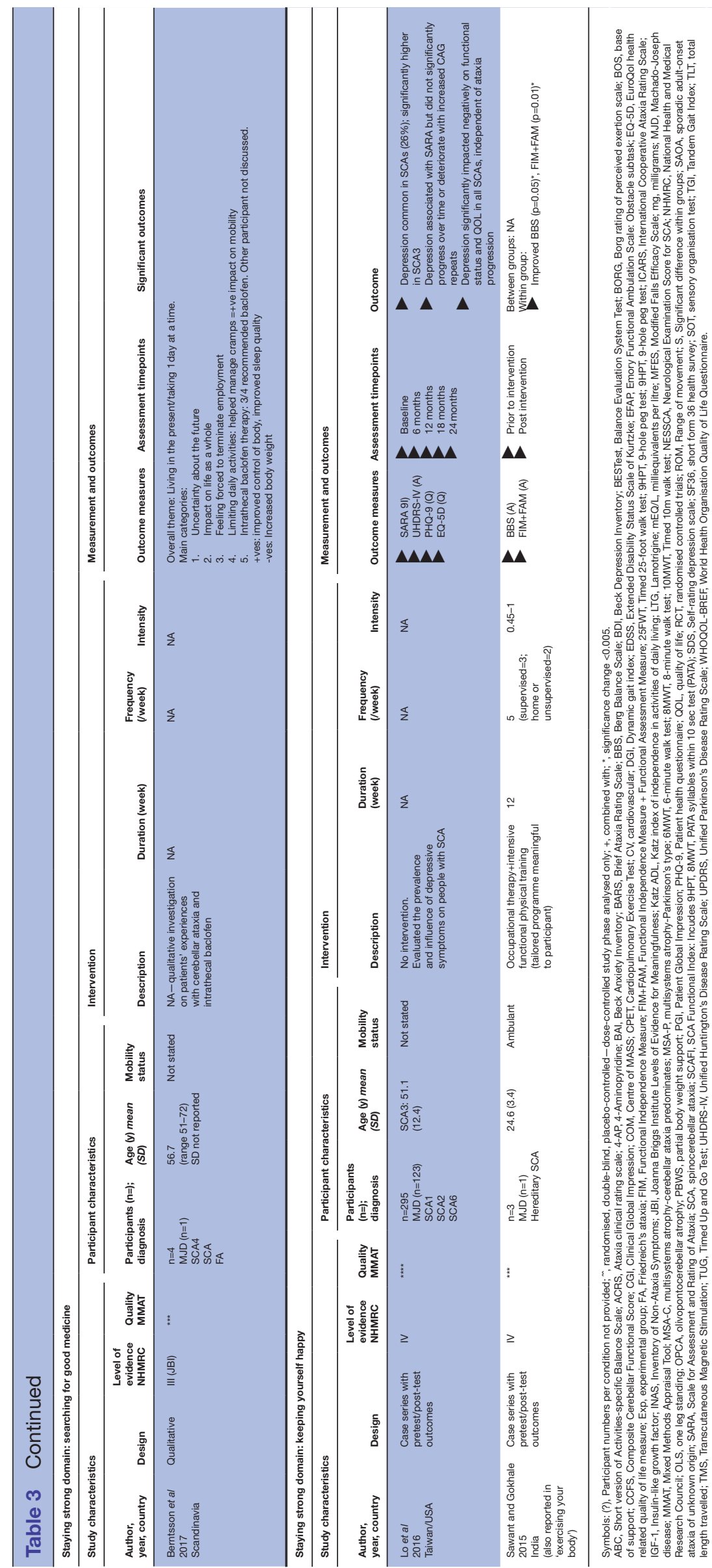

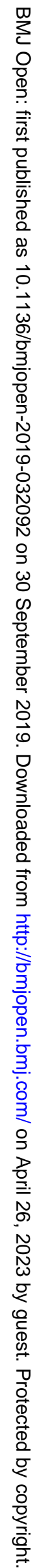


Table 4 Quality assessment of included studies using the Mixed Methods Appraisal Tool (MMAT)*

\begin{tabular}{|c|c|c|c|c|c|c|c|c|c|c|c|c|c|c|c|c|c|c|}
\hline \multirow[b]{2}{*}{ Author(s)† } & \multicolumn{4}{|c|}{ Qualitative } & \multicolumn{4}{|l|}{ Quantitative RCT } & \multicolumn{4}{|c|}{ Quantitative non-random } & \multicolumn{4}{|c|}{ Quantitative descriptive } & \multirow[b]{2}{*}{ Total } & \multirow[b]{2}{*}{ Scor } \\
\hline & $\begin{array}{l}\text { Sources } \\
\text { of data }\end{array}$ & $\begin{array}{l}\text { Process } \\
\text { for } \\
\text { analysis }\end{array}$ & Context & $\begin{array}{l}\text { Researchers' } \\
\text { t influence }\end{array}$ & Randomisation & Blinding & $\begin{array}{l}\text { Outcome } \\
\text { data }\end{array}$ & $\begin{array}{l}\text { Dropout } \\
\text { rate }\end{array}$ & $\begin{array}{l}\text { Selection } \\
\text { bias }\end{array}$ & $\begin{array}{l}\text { Appropriate } \\
\text { measurements }\end{array}$ & $\begin{array}{l}\text { Compared } \\
\text { groups }\end{array}$ & Outcome data & $\begin{array}{l}\text { Source } \\
\text { strategy }\end{array}$ & $\begin{array}{l}\text { Methods of } \\
\text { analysis }\end{array}$ & Context & Reflexivity & & \\
\hline $\begin{array}{l}\text { Arpa et al } \\
2015\end{array}$ & & & & & & & & & 1 & 1 & 1 & 1 & & & & & $4 / 4$ & 100 \\
\hline $\begin{array}{l}\text { Assadi et al } \\
2007\end{array}$ & & & & & 0 & 1 & 1 & 1 & & & & & & & & & $3 / 4$ & 75 \\
\hline $\begin{array}{l}\text { Berntsson et al } \\
2017\end{array}$ & 0 & 1 & 1 & 1 & & & & & & & & & & & & & $3 / 4$ & 75 \\
\hline $\begin{array}{l}\text { Conte et al } \\
2017\end{array}$ & & & & & & & & & 1 & 1 & 1 & 1 & & & & & $4 / 4$ & 100 \\
\hline $\begin{array}{l}\text { de Oliveira } \\
\text { et al } 2015\end{array}$ & & & & & & & & & 1 & 1 & 1 & 1 & & & & & $4 / 4$ & 100 \\
\hline $\begin{array}{l}\text { de Oliveira } \\
\text { et al } 2018\end{array}$ & & & & & & & & & 1 & 0 & 1 & 0 & & & & & $2 / 4$ & 50 \\
\hline $\begin{array}{l}\text { Fonteyn et al } \\
2014\end{array}$ & & & & & & & & & 1 & 1 & 1 & 1 & & & & & $4 / 4$ & 100 \\
\hline $\begin{array}{l}\text { Giordano et al } \\
2013\end{array}$ & & & & & & & & & 0 & 1 & 0 & 1 & & & & & $2 / 4$ & 50 \\
\hline Im et al 2017 & & & & & & & & & 1 & 1 & 1 & 1 & & & & & $4 / 4$ & 100 \\
\hline Kaut et al 2014 & & & & & 1 & 1 & 1 & 1 & & & & & & & & & $4 / 4$ & 100 \\
\hline Lei et al 2016 & & & & & 0 & 0 & 1 & 1 & & & & & & & & & $2 / 4$ & 50 \\
\hline $\begin{array}{l}\text { Leonardi et al } \\
2017\end{array}$ & & & & & & & & & 1 & 1 & 1 & 1 & & & & & $4 / 4$ & 100 \\
\hline Liu et al 2005 & & & & & & & & & 0 & 1 & 1 & 1 & & & & & $3 / 4$ & 75 \\
\hline Lo et al 2016 & & & & & & & & & & & & & 1 & 1 & 1 & 1 & $4 / 4$ & 100 \\
\hline $\begin{array}{l}\text { Monte et al } \\
2003\end{array}$ & & & & & & & & & 0 & 1 & 0 & 1 & & & & & $2 / 4$ & 50 \\
\hline $\begin{array}{l}\text { Sanz-Gallego } \\
\text { et al } 2014\end{array}$ & & & & & & & & & 1 & 1 & 1 & 0 & & & & & $3 / 4$ & 75 \\
\hline $\begin{array}{l}\text { Saute et al } \\
2014\end{array}$ & & & & & 1 & 1 & 1 & 1 & & & & & & & & & $4 / 4$ & 100 \\
\hline $\begin{array}{l}\text { Sawant and } \\
\text { Gokhale } 2015\end{array}$ & & & & & & & & & 0 & 1 & 1 & 1 & & & & & $3 / 4$ & 75 \\
\hline $\begin{array}{l}\text { Schulte et al } \\
2001\end{array}$ & & & & & 0 & 0 & 1 & 1 & & & & & & & & & $2 / 4$ & 50 \\
\hline $\begin{array}{l}\text { Shiga et al } \\
2002\end{array}$ & & & & & & & & & 0 & 1 & 1 & 1 & & & & & $3 / 4$ & 75 \\
\hline Silva et al 2010 & & & & & & & & & 1 & 1 & 1 & 1 & & & & & $4 / 4$ & 100 \\
\hline $\begin{array}{l}\text { Tabbassum } \\
\text { et al } 2013\end{array}$ & & & & & & & & & 0 & 1 & 0 & 0 & & & & & $1 / 4$ & 25 \\
\hline Takei et al 2004 & & & & & & & & & 0 & 1 & 1 & 1 & & & & & $3 / 4$ & 75 \\
\hline Takei et al 2010 & & & & & & & & & 0 & 1 & 1 & 0 & & & & & $2 / 4$ & 50 \\
\hline Tsai et al 2017 & & & & & & & & & 1 & 1 & 1 & 1 & & & & & $4 / 4$ & 100 \\
\hline $\begin{array}{l}\text { Wang et al } \\
2018\end{array}$ & & & & & 1 & 1 & 1 & 1 & & & & & & & & & $4 / 4$ & 100 \\
\hline $\begin{array}{l}\text { Wessel et al } \\
1997\end{array}$ & & & & & 0 & 1 & 1 & 1 & & & & & & & & & $3 / 4$ & 75 \\
\hline Yang et al 2011 & & & & & & & & & 1 & 0 & 1 & 1 & & & & & $3 / 4$ & 75 \\
\hline $\begin{array}{l}\text { Zesiewicz et al } \\
2012\end{array}$ & & & & & 1 & 1 & 1 & 0 & & & & & & & & & $3 / 4$ & 75 \\
\hline
\end{tabular}

A mixed-methods studies column was not included as no mixed-method studies were reviewed.

†D'Abreu et al 2010 was not scored (expert opinion excerpt).

1 , criterion met; 0 , criteria not met or unable to determine; RCT, randomised controlled trials.

\section{Study setting}

Of the 27 experimental studies, 12 were conducted under supervision of a health professional in the outpatient setting, ${ }^{40} 46-49525659606263$ two of which included an additional unsupervised home programme. ${ }^{52} 63$ In the remaining 15 studies, participants self-administered medications in their homes. ${ }^{30} 42-4549-5153546465$ The qualitative $^{37}$ and longitudinal observational studies ${ }^{61}$ were conducted face to face in an outpatient Neurology clinic. Study setting was not relevant to the expert opinion excerpt. ${ }^{1}$ Assessments were carried out in the inpatient setting in three studies, ${ }^{4155} 57$ outpatient setting for 12 studies, ${ }^{30} 42-4549-5153546465$ both in two studies, ${ }^{4157}$ while all follow-up took place in the outpatient setting. 


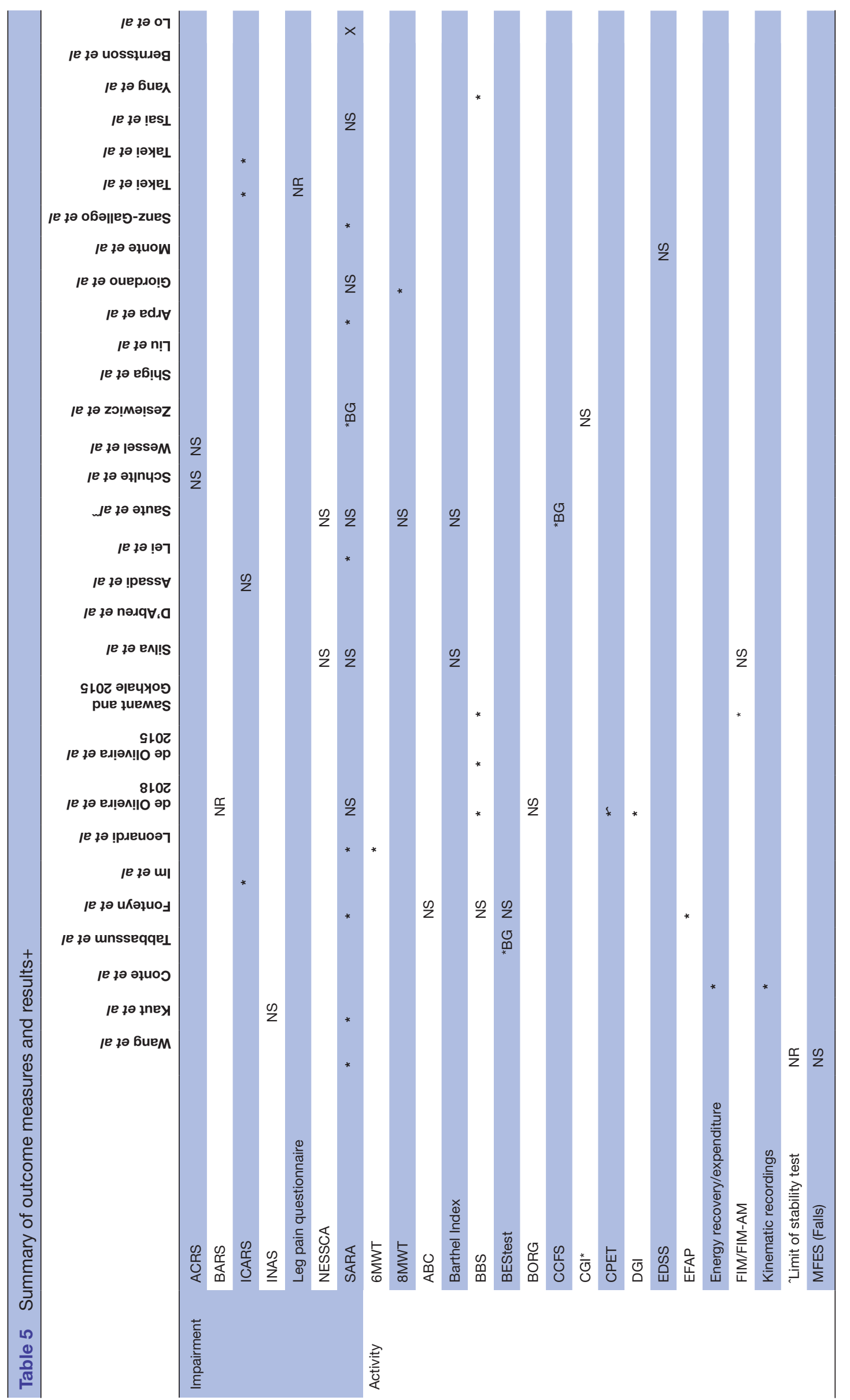




\section{Interventions}

A range of interventions have been explored, both pharmacological and non-pharmacological. Overall, no pharmacological interventions are currently recommended for use by indivudals with MJD. Non-pharmacological, exercise-based interventions, have had a positive impact on walking and moving around. Intervention types have been described under each of their corresponding domains in the 'Staying Strong' Framework (see table 3 and online supplementary table 1 ). In relation to the International Classification of Functioning, Disability and Health framework, ${ }^{67}$ no interventions in this review targeted the participation level, but focussed predominantly on the body functions and structures level and activity level.

\section{Exercising your body}

Thirteen studies discussed interventions which aligned with 'exercising your body'. 140 46-48 52 56-60 6263 Exercise in general was reported to be beneficial in one study. ${ }^{1}$ Specific interventions could be separated into three types of training: (1) walking training, (2) task specific training and (3) balance training. All studies related to 'exercising your body' reported significant findings, although only three of the 13 studies had a control group. Interventions varied in type, duration and frequency. Intervention sessions occurred on average for $51 \mathrm{~min}$ duration, 2.7 times a week for 8 weeks. Dosages such as repetitions completed per session or intensity, in terms of effort per session, were not reported. Rest periods were reported in one study. $^{47}$

\section{Walking practice}

Four studies investigated interventions that aligned to walking practice 47565859 including training on a treadmill, ${ }^{56}$ over ground walking ${ }^{59}$ and walking with a wide base of support. ${ }^{47}$ All significantly improved either balance, ${ }^{4758}$ ataxia $^{5659}$ and/or walking ability. ${ }^{475659}$

\section{Task-specific training}

Two studies investigated task-specific training through ADL training alone ${ }^{52}$ or in combination with strength, balance, coordination, walking and cycling training. ${ }^{63}$ ADL training alone significantly improved depression scores, ${ }^{52}$ but when combined with other task-specific training, balance and function also improved significantly after 12 weeks. $^{63}$

\section{Balance practice}

Six studies explored interventions to challenge balance: balance training alone ${ }^{62}$ or in conjunction with 'exergames $^{40}$; a wearable proprioceptive stabiliser $^{60}$; core stability training ${ }^{48}$; stochastic vibration therapy ${ }^{46}$ and task-specific training. ${ }^{63}$ Significant improvements (both between and within groups) in balance, ${ }^{48}$ ataxia severity $^{404660}$ and walking ${ }^{4660}$ were found. One study combined stem cell therapy with balance training (see below in 'searching for good medicine'). ${ }^{57}$

\section{Searching for good medicine}

Seventeen studies evaluated interventions that aligned with 'searching for good medicine'. Fourteen different pharmacological interventions were explored, one in combination with balance training, ${ }^{57}$ as well as one non-pharmacological intervention (transcutaneous magnetic stimulation (TMS)). No studies evaluated traditional medicine or complementary medicine use. ${ }^{68}$ One study (expert opinion) recommended medications to minimise the sequalae of impairments as a result of MJD (ie, levodopa for dystonia, pain relief for pain). ${ }^{1}$ While some therapies demonstrated potential to reduce ataxia (valproic acid, ${ }^{41}$ lithium carbonate, ${ }^{42}$ varenicline) ${ }^{45}$ and improve function (lithium carbonate, ${ }^{42}$ TMS), ${ }^{49}$ efficacy had not been demonstrated. None of the interventions were recommended for use by individuals with $\mathrm{MJD}^{9}$ (table 3).

\section{Keeping yourself happy}

Two studies aligned with 'keeping yourself happy'.37 61 Depression was found to have a significant negative impact on functional status and QOL, independent of ataxia, with suicidal ideation more common in MJD than in SCA1, SCA2 or SCA6. ${ }^{61}$ Participants living with ataxia shared the devastating impact of the disease on their social life, mood, parental roles, ADLs and employment, but recommended living in the present and taking 1 day at a time. ${ }^{37}$ Exercise was reported to help individuals with MJD cope and gain a sense of control over their disease. ${ }^{1}$ However, only one study explored individualised interventions designed to promote both physical and psychosocial well-being. ${ }^{52}$ Nine studies included measures of QOL or depression to evaluate their intervention $42434552-54586466$ but only two studies ${ }^{5354}$ demonstrated significant improvements in those measures (table 5). ${ }^{53}$ The remainder reported either non-significant findings or did not report significance levels.

\section{Something important to do}

Two studies aligned with having 'something important to do'. Support from employers was important to maintain work roles. ${ }^{37}$ Loss of meaningful employment, lack of support from employers or changes to roles as a parent or provider had a negative impact on mood and identity. ${ }^{37}$ Only one study evaluated an intervention tailored to the goals/needs of the participant. ${ }^{52}$ Depression scores improved, but measures of function and QOL failed to reach significance. ${ }^{52}$ No other included studies explored goal orientated or task-specific training or training based on individual goals/priorities/interests.

\section{Going country}

No studies aligned with 'going country'. All studies were conducted either in a hospital or research facility with the exception of two studies that included an unsupervised home programme. ${ }^{52} 63$ No studies were found that explored 'going country', community participation, community engagement, vocational rehabilitation, outdoor mobility, sport and/or recreation in relation to mobility for individuals with MJD. 


\section{Families helping each other}

No studies aligned with 'families helping each other'. No studies considered the influence of family support, interventions or rehabilitation with family, or the role of families in supporting mobility and function for individuals with MJD.

\section{DISCUSSION}

The purpose of this review was to map the range of interventions/strategies trialled for people with MJD to enhance walking and moving around and to align those interventions with the 'Staying Strong' Framework developed by individuals and families with MJD from the Groote Eylandt Archipeligo. Studies were typically of low quality and focused on what is largely staying strong on the outside: 'exercising your body' (walking training, balance training or task-specific training) and 'searching for good medicine' (various oral medicines, injectable medicines and non-pharmacological medicines). Few studies explored the impact on mobility of having 'something important to do' (ie, goal orientated, or task specific training based on individual goals/priorities/ interests) or strategies for 'keeping yourself happy'. No studies in this review considered the impact on mobility of 'going country' (community participation, outdoor mobility, sport/recreation) or 'families helping each other' (the impact or relationship of family support on functional mobility). This review thereby highlights an opportunity for meaningful, individualised, person-centred interventions to promote physical and psychosocial function, consistent with the views of families with MJD in Australia, ${ }^{18}$ and those living with ataxia in other parts of the world..$^{670}$

\section{Exercising your body}

Overall, exercise or physical activity interventions were found to have positive effects on mobility for individuals with MJD and to be generally safe, inexpensive and in current use. The most effective interventions and the optimal dosage could not be determined, due to heterogeneity of outcome measures and study designs. However, studies that engaged participants in at least 50 min training, at least 2-3 times each week, for approximately 4 weeks, demonstrated improvement. This finding is consistent with ataxia research more broadly, that has shown higher intensity rehabilitation to be more effective (60 min, 2 days per week) than less intensive training. ${ }^{11}$ Interestingly, no studies evaluated incidental physical activity or participants' level of activity outside of the intervention, unlike studies in other progressive conditions including Huntington's disease (HD), multiple sclerosis and Parkinson's disease (PD) literature. ${ }^{71} 72$ Programmes and interventions that promote participation and an active lifestyle have well known benefits on mobility and well-being for individuals living with neurological disorders. ${ }^{73}$ Yet the amount of exercise suggested to bring benefit for people with MJD and other ataxias ${ }^{11}$ suggests that lifestyle-orientated programmes that extend well beyond a 4 -week intervention are required. ${ }^{74}$

\section{Searching for good medicine}

Consistent with perspectives of families with MJD from the Groote Eylandt Archipelago, ${ }^{18}$ this review highlights the continued search for good medicine for individuals with MJD. The impact of traditional medicines or nutritional supplements on functional mobility for those with MJD has not been studied as it has in HD and PD. ${ }^{75} 76$ Furthermore, none of the many medications that were evaluated are currently indicated for MJD with most studies assessing drug safety with small samples. Notwithstanding, in this review, individuals with MJD were better represented in pharmacological studies than in studies on physiotherapeutic interventions. While large sample size recruitment is an inevitable challenge in rare disease research, ${ }^{16}$ sample homogeneity within studies will be important moving forward to generate strong clinical recommendations for those with MJD. ${ }^{9}$ Consistent with other ataxias, current recommendations for pharmacological management for those with MJD relate largely to managing the sequalae of disease, such as spasticity, sleeping difficulties and incontinence. ${ }^{19}$

\section{Going country}

In this study and across all SCAs, research to explore community-based interventions in the context of an individual's environment or lifestyle is lacking, despite known benefits of engagement in sport, recreation and leisure activities for those with disabilities. ${ }^{77}$ Dance and participation in sport are some activities that have been evaluated for those with other neurodegenerative conditions. ${ }^{78} 79$ While going country may be culturally and contextually specific to Aboriginal families with MJD in the Top End of Australia, individuals with ataxia in other parts of the world share similar views, relevant to their own context. ${ }^{80}$ Participation in outdoor sports, self-developed exercises, team sports or community-based exercise classes, while beneficial physically, have also been found to promote self-esteem and well-being. ${ }^{70}$ Outdoor activities have helped individuals with ataxia manage depression and focus on living life to the fullest. ${ }^{70}$ Individuals with MJD generally remain ambulant up to 10 years following onset of symptoms, ${ }^{4}$ leaving opportunities for engagement in sport and recreational activities outside of a facility and in the community. Impairment focused intervention programmes restricted to indoor clinical facilities may overlook functional benefits that could be gained through participation in interventions that are fun, enjoyable and meaningful to the person. ${ }^{70}$ Research to evaluate the benefits of such interventions on mobility is warranted, for those with MJD and HAs more broadly.

\section{Something important to do and keeping yourself happy}

Disappointingly, having 'something important to do' and 'keeping yourself happy' were discussed minimally in the literature. The impact of depression on QOL for people 
with SCAs is alarming, particularly the significantly higher rates of suicidal ideation for those with MJD ${ }^{61}$ While a number of studies in this review included measures of depression and QOL, ${ }^{42} 434552-54586466$ interventions tested appeared to have little impact on either. The sensitivity of the measures used over the generally short intervention period should be taken into consideration. ${ }^{82}$ On the other hand, this may highlight a need for more individualised interventions that target both physical and psychosocial well-being more effectively. The importance of self-selected meaningful exercise has been echoed by individuals with other degenerative ataxias, finding selfchosen activities that offer physical challenge and personally meaningful rewards, provide a sense of achievement, satisfaction and motivation to carry on. ${ }^{70}$ While evaluation of the efficacy of individualised interventions does present challenges, ${ }^{83}$ programmes such as ParkFIT for PD in the Netherlands ${ }^{84}$ and Engage-HD for people with $\mathrm{HD}$ in the $\mathrm{UK}^{71}$ have provided examples on how these challenges can be overcome. ${ }^{73}$

\section{Families helping each other}

It is perhaps surprising, considering MJD is an autosomal-dominant disease, that no studies discussed the inclusion of family members as study participants. The devastating impact families face with autosomal-dominant neurodegenerative diseases is well known. ${ }^{86-88}$ While family support, peer socialisation and support through physical activity is a facilitator for engagement in physical activity for people with neurodegenerative diseases ${ }^{89}$ no studies in this review discussed these factors. Furthermore, no studies evaluated group-based interventions, although the involvement of peers or family members in physiotherapeutic interventions can enhance motivation, social support and long-term participation in physical activity. ${ }^{90}$ There is no doubt that the role of families is worthy of further investigation.

\section{Outcome measures}

Consensus and validation of outcome measures for individuals with MJD is required, with consideration given to outcomes in terms of all the domains of the Staying Strong' Framework. Reaching agreement on recommended outcome measures for people with MJD will be an important step for future clinical trials and development of clinical guidelines for management of MJD over the course of the disease. Guidelines for people with inherited ataxias have been developed,$^{91}$ as have guidelines for those with Friedreich's ataxia, ${ }^{92}$ but the particular issues individuals and their families with MJD face require specific attention.

\section{Limitations}

There were few studies that contained participants exclusively with MJD, so it is difficult to draw conclusions specifically for people with MJD. However, the findings do highlight the dearth of evidence relating to walking and moving around for individuals with MJD. While there may be interventions trialled that have had a positive impact on functional mobility, they are yet to be evaluated.
Additional studies may exist that focus on domains such as having 'something important to do', 'keeping yourself happy' and 'families helping each other', but these may not have been found on initial searches if they did not include a functional mobility-related keyword. However, search strategies in this review were used to identify interventions that promoted functional mobility through staying strong both on the inside and outside.

\section{CONCLUSION}

This scoping review mapped studies that investigated the range of interventions to keep people with MJD walking and moving around. Findings were compared with "what works best' according to families with MJD from the Groote Eylandt Archipelago. Interventions which aligned with their 'Staying Strong' Framework ${ }^{18}$ were largely limited to staying strong on the outside (physically), with little reflection on staying strong on the inside (emotionally, mentally and spiritually). The findings of this review suggest future research is required to investigate the benefit of lifestyle activity programmes that address both physical and psychosocial well-being for families with MJD. Detailed reporting on the physical and psychosocial aspects of these interventions, and on the development and delivery of these programmes will help guide programme implementation for health service providers and clinicians working alongside families with MJD. The 'Staying Strong' Framework presented community and culturally founded needs that provided a way to identify significant gaps in the literature and highlight where those needs have not been met. Considerably more effort in culturally informed research is required.

\section{Author affiliations \\ 1James Cook University, College of Healthcare Sciences, Cairns, Queensland, Australia \\ ${ }^{2}$ Machado-Joseph Disease Foundation, Alyangula, Northern Territory, Australia ${ }^{3}$ James Cook University, College of Healthcare Sciences, Townsville, Queensland, Australia \\ ${ }^{4}$ School of Public Health, Tropical Medicine and Rehabilitation Sciences, James Cook University, Cairns, Queensland, Australia \\ ${ }^{5}$ Northern Institute, Charles Darwin University, Darwin, Northern Territory, Australia}

Acknowledgements The authors would like to acknowledge and thank Aboriginal families with MJD from the Groote Eylandt Archipelago and in Ngukurr who developed the 'Staying Strong' Framework and welcomed the researchers to their country.

Contributors Authors JJC, RNB, AL, ARC designed the study. JJC, JQ, MS and RNB were involved in study selection, quality assessment and data extraction. JJC, $\mathrm{JL}, \mathrm{GL}$ and RNB collaborated on data analysis and interpretation. The manuscript was drafted by JJC, RNB, AL and ARC. All authors approved the final version of the manuscript.

Funding The authors would like to thank the MJD Foundation, Anindilyakwa Land Council and Lowitja Institute Aboriginal and Torres Strait Islander Health CRC (Lowitja Institute CRC) (grant ID: 017-SF-005) (https://www.lowitja.org.au) for funding this work.

Competing interests None declared.

Patient consent for publication Not required.

Provenance and peer review Not commissioned; externally peer reviewed. 
Data availability statement All data relevant to the study are included in the article or uploaded as supplementary information.

Open access This is an open access article distributed in accordance with the Creative Commons Attribution Non Commercial (CC BY-NC 4.0) license, which permits others to distribute, remix, adapt, build upon this work non-commercially, and license their derivative works on different terms, provided the original work is properly cited, appropriate credit is given, any changes made indicated, and the use is non-commercial. See: http://creativecommons.org/ licenses/by-nc/4.0/.

\section{REFERENCES}

1. D'Abreu A, França MC, Paulson HL, et al. Caring for MachadoJoseph disease: current understanding and how to help patients. Parkinsonism Relat Disord 2010;16:2-7.

2. Massey L, Jane A, Lindop N, et al. Disability Audit - NE Arnhem Land/NT Gulf - A Snapshot of Indigenous Australian Disability in the Very Remote Communities of the Groote Eylandt Archipelago (Angurugu, Umbakumba, Milyakburra), Elcho Island (Galiwin'ku), and Ngukurr (including Urapunga). Australian Indigenous Health Bulletin 2013;13.

3. Ruano L, Melo C, Silva MC, et al. The global epidemiology of hereditary ataxia and spastic paraplegia: a systematic review of prevalence studies. Neuroepidemiology 2014;42:174-83.

4. MJD Foundation. MJD Foundation - Disability Service Delivery Model - A review of the MJD Foundation's disability service delivery model: contrast and comparison to traditional disability service models. Alyangula, Northern Territory: MJD Foundation, 2018.

5. de Araujo M, Raposo M, Kazachkova N, et al. Trends in the epidemiology of spinocerebellar ataxia type 3/Machado-Joseph disease in the Azores Islands, Portugal. JSM Brain Sci 2016;1.

6. MacMillan J. Machado Joseph Disease SCA3. [lecture notes on the Internet] Herston. Australia: Genetic Health Queensland, 2011. http:// mjd.org.au/2-what-is-mjd.html [Accessed 1 Jan 2018].

7. Australian Bureau of Statistics. 2075.0 - Census of Population and Housing - Counts of Aboriginal and Torres Strait Islander Australians, 2016. Table 11: Census Counts, Indigenous Regions - Northern Territory, 2016: Australian Bureau of Statistics; 2017 [cited 3 Apr 2018]. Available: http://www.abs.gov.au/AUSSTATS/abs@.nsf/ DetailsPage/2075.02016? OpenDocument [Accessed 3 Apr 2018]

8. Ilg W, Bastian AJ, Boesch S, et al. Consensus paper: management of degenerative cerebellar disorders. Cerebellum 2014;13:248-68.

9. Zesiewicz TA, Wilmot G, Kuo S-H, et al. Comprehensive systematic review summary: treatment of cerebellar motor dysfunction and ataxia: report of the Guideline development, Dissemination, and Implementation Subcommittee of the American Academy of Neurology. Neurology 2018;90:464-71.

10. Fonteyn EMR, Keus SHJ, Verstappen CCP, et al. The effectiveness of allied health care in patients with ataxia: a systematic review. $J$ Neurol 2014;261:251-8.

11. Milne SC, Corben LA, Georgiou-Karistianis N, et al. Rehabilitation for individuals with genetic degenerative ataxia: a systematic review. Neurorehabil Neural Repair 2017;31:609-22.

12. Saute JAM, Jardim LB. Machado Joseph disease: clinical and genetic aspects, and current treatment. Expert Opin Orphan Drugs 2015;3:517-35

13. Miyai I, Ito $\mathrm{M}$, Hattori $\mathrm{N}$, et al. Cerebellar ataxia rehabilitation trial in degenerative cerebellar diseases. Neurorehabil Neural Repair 2012;26:515-22.

14. Synofzik M, llg W. Motor training in degenerative spinocerebellar disease: ataxia-specific improvements by intensive physiotherapy and exergames. Biomed Res Int 2014;2014:583507

15. Ilg W, Brötz D, Burkard S, et al. Long-Term effects of coordinative training in degenerative cerebellar disease. Mov Disord 2010;25:2239-46.

16. Ilg W, Schatton C, Schicks J, et al. Video game-based coordinative training improves ataxia in children with degenerative ataxia. Neurology 2012;79:2056-60.

17. Ilg W, Synofzik M, Brötz D, et al. Intensive coordinative training improves motor performance in degenerative cerebellar disease. Neurology 2009;73:1823-30.

18. Carr JJ, Lalara J, Lalara G, et al. 'Staying strong on the inside and outside' to keep walking and moving around: perspectives from Aboriginal people with Machado Joseph disease and their families from the Groote Eylandt Archipelago, Australia. PLoS One 2019;14:e0212953.

19. Gray C, Macniven R, Thomson N. Review of physical activity among Indigenous people. Australian Indigenous HealthInfoNet 2013;13:1-17.
20. Dahlberg E, Hamilton S, Hamid F, et al. Indigenous Australians perceptions' of physical activity: a qualitative systematic review. Int J Environ Res Public Health 2018;15:1492.

21. Machado Joseph Disease Foundation. About us: what we do: MJD Foundation; 2017 [cited 16 Mar 2017]. Available: http://mjd.org.au/ 7-about-us.html [Accessed 12 Mar 2017].

22. Arksey H, O'Malley L. Scoping studies: towards a methodological framework. Int J Soc Res Methodol 2005;8:19-32.

23. Levac D, Colquhoun H, O'Brien KK. Scoping studies: advancing the methodology. Implement Sci 2010;5:69.

24. Munn Z, Peters MDJ, Stern C, et al. Systematic review or scoping review? Guidance for authors when choosing between a systematic or scoping review approach. BMC Med Res Methodol 2018;18:143.

25. Tricco AC, Lillie E, Zarin W, et al. PRISMA extension for scoping reviews (PRISMA-ScR): checklist and explanation. Ann Intern Med 2018;169:467-73.

26. Kawaguchi Y, Okamoto T, Taniwaki M, et al. CAG expansions in a novel gene for Machado-Joseph disease at chromosome 14q32.1. Nat Genet 1994;8:221-8.

27. Takiyama $\mathrm{Y}$, Nishizawa M, Tanaka $\mathrm{H}$, et al. The gene for MachadoJoseph disease maps to human chromosome 14q. Nat Genet 1993:4:300-4.

28. Trujillo-Martín MM, Serrano-Aguilar P, Monton-Álvarez F, et al. Effectiveness and safety of treatments for degenerative ataxias: a systematic review. Mov Disord 2009;24:1111-24.

29. Braga Neto P, Pedroso JL, Kuo S-H, et al. Current concepts in the treatment of hereditary ataxias. Arq Neuropsiquiatr 2016;74:244-52.

30. Assadi M, Campellone JV, Janson CG, et al. Treatment of spinocerebellar ataxia with buspirone. J Neurol Sci 2007;260:143-6.

31. Martins C, Rodrigues E, Oliveira L. Physical therapy approach to spinocerebellar ataxia: a systematic review. Fisioter e Pesqui 2013;20:293-8

32. Liberati A, Altman DG, Tetzlaff J, et al. The PRISMA statement for reporting systematic reviews and meta-analyses of studies that evaluate health care interventions: explanation and elaboration. $J$ Clin Epidemiol 2009;62:e1-34.

33. Pham MT, Rajić A, Greig JD, et al. A scoping review of scoping reviews: advancing the approach and enhancing the consistency. Res Synth Methods 2014;5:371-85.

34. National Collaborating Centre for Methods and Tools. Appraising qualitative, quantitative and mixed method studies included in mixed studies reviews: the MMAT Hamilton, ON: McMaster University, 2015. Available: http://www.nccmt.ca/knowledgerepositories/search/232\%20(accessed\%20May\%202017 [Accessed 1 Sep 2017].

35. National Health and Medical Research Council. NHMRC levels of evidence and grades for recommendations for guideline developers. Canberra, ACT: Australia, 2009.

36. Joanna Briggs Institute Levels of Evidence and Grades of Recommendation Working Party. New JBI levels of evidence. Joanna Briggs Institute, 2014.

37. Berntsson SG, Landtblom A-M, Flensner G. Cerebellar ataxia and intrathecal baclofen therapy: focus on patients' experiences. PLOS One 2017;12:e0180054.

38. NVivo 12 [program]. Australia 2018.

39. Sandelowski M. Whatever happened to qualitative description? Res Nurs Health 2000;23:334-40.

40. Wang R-Y, Huang F-Y, Soong B-W, et al. A randomized controlled pilot trial of game-based training in individuals with spinocerebellar ataxia type 3. Sci Rep 2018;8:7816.

41. Lei L-F, Yang G-P, Wang J-L, et al. Safety and efficacy of valproic acid treatment in SCA3/MJD patients. Parkinsonism Relat Disord 2016;26:55-61.

42. Saute JAM, de Castilhos RM, Monte TL, et al. A randomized, phase 2 clinical trial of lithium carbonate in Machado-Joseph disease. Mov Disord 2014;29:568-73.

43. Schulte T, Mattern R, Berger K, et al. Double-blind crossover trial of trimethoprim-sulfamethoxazole in spinocerebellar ataxia type 3/ Machado-Joseph disease. Arch Neurol 2001;58:1451-7.

44. Wessel K, Langenberger K, Nitschke MF, et al. Double-blind crossover study with physostigmine in patients with degenerative cerebellar diseases. Arch Neurol 1997;54:397-400.

45. Zesiewicz TA, Greenstein PE, Sullivan KL, et al. A randomized trial of varenicline (Chantix) for the treatment of spinocerebellar ataxia type 3. Neurology 2012;78:545-50.

46. Kaut $\mathrm{O}$, Jacobi $\mathrm{H}$, Coch $\mathrm{C}$, et al. A randomized pilot study of stochastic vibration therapy in spinocerebellar ataxia. Cerebellum 2014:13:237-42. 
47. Conte C, Serrao M, Cuius L, et al. Effect of restraining the base of support on the other biomechanical features in patients with cerebellar ataxia. Cerebellum 2018;17:264-75.

48. Tabbassum K, Zia N, Singh S, et al. Core stability training with conventional balance training improves dynamic balance in progressive degenerative cerebellar ataxia. Indian J Physiother Occup Therapy 2013;7:136-40.

49. Shiga $Y$, Tsuda T, Itoyama $Y$, et al. Transcranial magnetic stimulation alleviates truncal ataxia in spinocerebellar degeneration. $J$ Neurol Neurosurg Psychiatry 2002;72:124-6.

50. Liu C-S, Hsu H-M, Cheng W-L, et al. Clinical and molecular events in patients with Machado-Joseph disease under lamotrigine therapy. Acta Neurol Scand 2005;111:385-90.

51. Monte TL, Rieder CRM, Tort AB, et al. Use of fluoxetine for treatment of Machado-Joseph disease: an open-label study. Acta Neurol Scand 2003;107:207-10.

52. Silva RCR, Saute JAM, Silva ACF, et al. Occupational therapy in spinocerebellar ataxia type 3: an open-label trial. Braz J Med Biol Res 2010;43:537-42.

53. Takei A, Fukazawa T, Hamada $\mathrm{T}$, et al. Effects of Tandospirone on " 5 HT1A Receptor-Associated Symptoms" in Patients with MachadoJosephe Disease. Clin Neuropharmacol 2004;27:9-13.

54. Takei A, Hamada S, Homma S, et al. Difference in the effects of tandospirone on ataxia in various types of spinocerebellar degeneration: an open-label study. Cerebellum 2010;9:567-70.

55. Tsai Y-A, Liu R-S, Lirng J-F, et al. Treatment of spinocerebellar ataxia with mesenchymal stem cells: a phase I/lla clinical study. Cell Transplant 2017;26:503-12.

56. Fonteyn EMR, Heeren A, Engels J-JC, et al. Gait adaptability training improves obstacle avoidance and dynamic stability in patients with cerebellar degeneration. Gait Posture 2014;40:247-51.

57. Yang $W-Z$, Zhang $Y, W u ~ F$, et al. Human umbilical cord blood-derived mononuclear cell transplantation: case series of 30 subjects with hereditary ataxia. $J$ Transl Med 2011;9:65.

58. de Oliveira LAS, Martins CP, Horsczaruk CHR, et al. Partial body Weight-Supported treadmill training in spinocerebellar ataxia. Rehabil Res Pract 2018;2018:7172686.

59. Im S-J, Kim Y-H, Kim K-H, et al. The effect of a task-specific locomotor training strategy on gait stability in patients with cerebellar disease: a feasibility study. Disabil Rehabil 2017;39:1002-8.

60. Leonardi L, Aceto MG, Marcotulli C, et al. A wearable proprioceptive stabilizer for rehabilitation of limb and gait ataxia in hereditary cerebellar ataxias: a pilot open-labeled study. Neurol Sci 2017:38:459-63.

61. Lo RY, Figueroa KP, Pulst SM, et al. Depression and clinical progression in spinocerebellar ataxias. Parkinsonism Relat Disord 2016;22:87-92.

62. Santos de Oliveira LA, Martins CP, Horsczaruk CHR, et al. Decreasing fall risk in spinocerebellar ataxia. $J$ Phys Ther Sci 2015;27:1223-5.

63. Sawant $P$, Gokhale P. Functional approach in spino-cerebellar Ataxia-Occupational therapy perspective. Indian J Physiother Occup Therapy 2015;9:223-8.

64. Giordano I, Bogdanow M, Jacobi $\mathrm{H}$, et al. Experience in a shortterm trial with 4-aminopyridine in cerebellar ataxia. $J$ Neurol 2013;260:2175-6.

65. Arpa J, Sanz-Gallego I, Medina-Báez J, et al. Subcutaneous insulinlike growth factor-1 treatment in spinocerebellar ataxias: an open label clinical trial. Mov Disord 2011;26:358-9.

66. Sanz-Gallego I, Rodriguez-de-Rivera FJ, Pulido I, et al. IGF-1 in autosomal dominant cerebellar ataxia - open-label trial. Cerebellum Ataxias 2014;1.

67. Rimmer JH. Use of the ICF in identifying factors that impact participation in physical activity/rehabilitation among people with disabilities. Disabil Rehabil 2006;28:1087-95.

68. World Health Organisation. WHO traditional medicine strategy: 20142023. Hong Kong, China: World Health Organisation, 2013.

69. Daker-White G, Greenfield J, Ealing J. "Six sessions is a drop in the ocean": an exploratory study of neurological physiotherapy in idiopathic and inherited ataxias. Physiotherapy 2013;99:335-40.

70. Cassidy E, Naylor S, Reynolds F. The meanings of physiotherapy and exercise for people living with progressive cerebellar ataxia: an interpretative phenomenological analysis. Disabil Rehabil 2018:40:894-904.

71. Quinn L, Trubey R, Gobat N, et al. Development and delivery of a physical activity intervention for people with Huntington disease: facilitating translation to clinical practice. J Neurol Phys Ther 2016;40:71-80.

72. Schmidt AL, Pennypacker ML, Thrush AH, et al. Validity of the StepWatch step activity monitor: preliminary findings for use in persons with Parkinson disease and multiple sclerosis. J Geriatr Phys Ther 2011;34:41-5.

73. Quinn L, Morgan D. From disease to health: physical therapy health promotion practices for secondary prevention in adult and pediatric neurologic populations. J Neurol Phys Ther 2017;41:S46-54

74. Motl RW. Lifestyle physical activity in persons with multiple sclerosis: the new kid on the MS block. Mult Scler 2014;20:1025-9.

75. Satoh T, Takahashi T, Iwasaki K, et al. Traditional Chinese medicine on four patients with Huntington's disease. Mov Disord 2009;24:453-5

76. Kim T-H, Cho K-H, Jung W-S, et al. Herbal medicines for Parkinson's disease: a systematic review of randomized controlled trials. PLOS One 2012;7:e35695.

77. Lord E, Patterson I. The benefits of physically active leisure for people with disabilities: an Australian perspective. Annals of Leisure Research 2008;11:123-44.

78. Aguiar LPC, da Rocha PA, Morris M. Therapeutic dancing for Parkinson's disease. Int J Gerontol 2016;10:64-70.

79. Donze C, Massot C, Hautecoeur P, et al. The practice of sport in multiple sclerosis: update. Curr Sports Med Rep 2017;16:274-9.

80. Thompson Coon J, Boddy K, Stein K, et al. Does participating in physical activity in outdoor natural environments have a greater effect on physical and mental wellbeing than physical activity indoors? A systematic review. Environ Sci Technol 2011:45:1761-72.

81. Kleim JA, Jones TA. Principles of experience-dependent neural plasticity: implications for rehabilitation after brain damage. J Speech Lang Hear Res 2008;51:S225-39.

82. Payakachat N, Ali MM, Tilford JM. Can the EQ-5D detect meaningful change? A systematic review. Pharmacoeconomics 2015;33:1137-54

83. Beck C, McSweeney JC, Richards KC, et al. Challenges in tailored intervention research. Nurs Outlook 2010;58:104-10.

84. van Nimwegen M, Speelman AD, Smulders K, et al. Design and baseline characteristics of the ParkFit study, a randomized controlled trial evaluating the effectiveness of a multifaceted behavioral program to increase physical activity in Parkinson patients. BMC Neurol 2010;10:70.

85. Speelman AD, van Nimwegen M, Bloem BR, et al. Evaluation of implementation of the ParkFit program: a multifaceted intervention aimed to promote physical activity in patients with Parkinson's disease. Physiotherapy 2014;100:134-41.

86. Vamos M, Hambridge J, Edwards M, et al. The impact of Huntington's disease on family life. Psychosomatics 2007;48:400-4.

87. Maxted C, Simpson J, Weatherhead S. An exploration of the experience of Huntington's disease in family dyads: an interpretative phenomenological analysis. J Genet Couns 2014;23:339-49.

88. Jona CMH, Labuschagne I, Mercieca E-C, et al. Families affected by Huntington's disease report difficulties in communication, emotional involvement, and problem solving. J Huntingtons Dis 2017;6:169-77.

89. Newitt R, Barnett F, Crowe M. Understanding factors that influence participation in physical activity among people with a neuromusculoskeletal condition: a review of qualitative studies. Disabil Rehabil 2016;38:1-10.

90. Morris J, Oliver T, Kroll T, et al. The importance of psychological and social factors in influencing the uptake and maintenance of physical activity after stroke: a structured review of the empirical literature. Stroke Res Treat 2012;2012:195249

91. Bonney H, de Silva R, Giunti P. Management of the ataxias towards best clinical practice. 3rd edn. Ataxia UK, 2016.

92. Corben LA, Lynch D, Pandolfo M, et al. Consensus clinical management guidelines for Friedreich ataxia. Orphanet $J$ Rare Dis 2014;9:184 